\title{
Preliminary Results of a New Experimental Model for Intratympanic Treatment
}

\author{
Kamil Aykal ${ }^{1}$ (D), Fazıl Necdet Ardıç ${ }^{1}$ (D), Funda Tümkaya ${ }^{1}$ (D), Emrah Yücel ${ }^{1}$ (D), Mehri Akarsu², \\ Cüneyt Orhan $\operatorname{Kara}^{1}$ (D), Emin Erdem² (D) \\ Original Investigation $\quad{ }^{1}$ Department of Otorhinolaryngology, Pamukkale University School of Medicine, Denizli, Turkey \\ ${ }^{2}$ Department of Chemistry, Pamukkale University School of Medicine, Denizli, Turkey
}

\section{Abstract}

ORCID IDs of the authors: K.A. 0000-0002-5863-5194; F.N.A. 0000-0003-4230-3141; F.T. 0000-0002-3213-8106; E.Y. 0000-0003-0819-6135; C. 0. K. $0000-0003-2219-4283$ E.E. 0000-0003-3442-332X.

Cite this article as: Aykal K, Ardıç FN, Tümkaya F, Yücel E, Akarsu M, Kara CO, et al. Preliminary Results of a New Experimental Model for Intratympanic Treatment. Turk Arch Otorhinolaryngol 2018; 56(4): 188-92.

This study was presented at the $1^{\text {st }}$ World Congress of Otology, June 30 - July 4 2015, Niigata, Japan.

Corresponding Author:

Fazıl Necdet Ardıç; fnardic@pau.edu.tr

Received Date: 18.04.2018

Accepted Date: 14.08.2018

(c) Copyright 2018 by 0fficial Journal of the Turkish Society of Otorhinolaryngology and Head and Neck Surgery Available online at www.turkarchotolaryngol.net DOI: 10.5152/ta0.2018.3467
Objective: Corticosteroids have been applied via transtympanic route for a long time to treat the inner ear disorders. A few animal models were used to answer the questions, "How much drug goes into the inner ear?" and "How far does the drug reach through the scala tympani and/or scala vestibuli?" However, the cerebrospinal fluid contamination poses a major problem. The aims of this study were to create a new sampling model showing the dexamethasone distribution in the inner ear and to provide more reliable data about drug concentrations.

Methods: Ten Hartley strain albino guinea pigs that weighted between 400 and $600 \mathrm{~g}$ were used. After dexamethasone application to the left ear, they were sacrificed at two time points: after 0.5 hours (Exp 1) and after 2 hours (Exp 2). The temporal bones were immediately dissected and put into liquid nitrogen for freezing. The apex, second turn, and basal turns of the cochlea and vestibule were separated, while the bone was in the frozen state. The samples were prepared and measured with ultraviolet (UV) spectroscopy.

Results: The total amount of dexamethasone was statistically higher in the left ear than the control ear. Although the basal turn and vestibule were the most prominent parts, there was no statistical difference between the different parts of the inner ear at 0.5 hours. The vestibule and the apex showed the highest level of dexamethasone at 2 hours.

Conclusion: Although the model has some limitations, it can measure dexamethasone concentrations and show the time variability in the inner ear.

Keywords: Inner ear, cochlea, intratympanic injection, dexamethasone

\section{Introduction}

Corticosteroids have shown beneficial effects in many inner ear diseases, and potential mechanisms have been demonstrated in animal studies (1-3). Corticosteroids pass through the cell membrane and join with the specific receptor proteins in the nucleus and cytoplasm of the target cells. When higher concentrations of dexamethasone are targeted in perilymph, very high drug doses have to be used systemically, which may cause serious side effects (1). Because of these side effects, intratympanic (IT) route is getting increasingly popular. Chandrasekhar et al. (4) have shown that dexamethasone applied intratympanicaly reaches much higher concentrations in perilymph than when applied intravenously. The experimental studies with immunohistochemical markers have shown that 4 $\mathrm{mg} / \mathrm{mL}$ dexamethasone administered via the IT route were connected intensively with the glucocorticoid receptors in the spiral ligament, organ of Corti, spiral ganglion, and vestibular epithelium $(2,3)$.

The basic questions for the IT route are the following: "How much drug goes into the inner ear?" and "How far does the drug reach through the scalas?" Animal models were constructed to measure the amount of the drug and to find a distribution pattern in the inner ear after the IT administration. The fundamental problem was the sampling of perilymph. Single samples from the round window, oval window, and basal turn or sequential sampling from the apical region were attempted (4-6). They were able to show drug concentrations in the perilymph. But the major concern was the contamination of perilymph with the cerebrospinal fluid (5). 
Further studies using markers and tissue-processing methods were also used to show the presence of drug in the certain regions of the inner ear (3). But they do not give any details regarding the drug concentration. Computer simulations have been developed based on the limited data for the estimation of drug amount in different parts of cochlea (7).

The aims of this study were to create a new sampling model showing the time-dependent dexamethasone distribution in the inner ear and to provide more reliable data about drug concentrations.

\section{Methods}

Our study was conducted at Pamukkale University Center of Experimental Research. The permission was obtained from the Ethics Committee of Pamukkale University School of Medicine (Date: 08/Jan/2013; No: 2013/01). The institutional guidelines regarding animal experimentation were followed.

In this study, 10 Hartley strain albino guinea pigs that weighted between 400 and $600 \mathrm{~g}$ were used. The guinea pigs were hosted in a controlled environment: $50 \%$ humidity and $16^{\circ} \mathrm{C}-21^{\circ} \mathrm{C}$ temperature. They were fed with special pellets and vitamin $\mathrm{C}$ (in the form of seasonal fresh fruits and vegetables). The room was illuminated following the 12-hour-light/dark cycle. We followed the guidelines of animal care and use in accordance with the International Declaration of Helsinki.

Experiment Protocol: All procedures were performed under general anesthesia. General anesthesia was achieved by giving $10 \mathrm{mg} / \mathrm{kg}$ xylazine $\mathrm{HCl}$ (Alfazyn 2\%, Alfasan, the Woerden, Netherlands) and $75 \mathrm{mg} / \mathrm{kg}$ ketamine $\mathrm{HCl}$ (Ketan's, Pfizer, Istanbul, Turkey) together, intraperitoneally. With this dose, anesthesia lasted for 60-90 minutes. One-third of the initial dose of the same mixture was injected again if further anesthesia was needed.

All guinea pigs underwent an otoscopic examination and had normal tympanic membranes. Dexamethasone (Dexoject, $4 \mathrm{mg}$ / $\mathrm{mL}$; Mefar, İstanbul, Turkey) was applied to left ears of the guinea pigs. Their right ears (nothing applied) were preserved as the control. On the scalp, a subcutaneous incision starting from the midline sagittal plan and combining orbital rim, extending to the vertebra was made. Periosteum was elevated, and temporal muscles, frontal, and parietal bones were observed. After temporal muscles were elevated, temporal bone's mastoid process and tympanic segment (bulla) were viewed. Bulla was drilled with a micro drill. Injections were applied via a 28 - gauge needle (approximately 0.20 to $0.30 \mathrm{ml}$ ) until the bulla was filled. After injection, the guinea pig was put in the sideways position so that the left ear was on facing upwards. Then, the bulla was cleaned by aspirator and washed by saline at 0.5 hours. The experiment was terminated at two different time points: 0.5 hours $(\operatorname{Exp} 1)$ or 2 hours (Exp 2).

Dissection and Preparation: After drug application, the guinea pigs were divided into two groups according to the waiting time before sacrificing ( 0.5 hours, 2 hours). At the end of the specified time period, the guinea pigs were sacrificed using an intracardiac potassium injection. After a large posterior incision, the soft tissue was removed. Temporal bones were separated from the skull by rough dissection. Then the squamous part, mastoid cortex, and tympanic bone were removed by micro rongeurs under the operating microscope. The cochlea of the guinea pig is mainly in the mastoid cavity. The samples that were wrapped in aluminum foil were placed in a liquid nitrogen tank and were allowed to freeze for 5 minutes (Figure 1). The specimens in the frozen state were brought up. The cochlea was divided into three parts (the apex, second turn, and basal turn) with a scalpel under the operating microscope. The vestibule was then removed separately. To prevent contamination, the scalpel was replaced for each new piece. So, four samples were taken from each of the temporal bone. The samples were placed in an Eppendorf tube and stored at $-5^{\circ} \mathrm{C}$.

Chemical Measurements: The samples were stored until the day of analysis at $-5^{\circ} \mathrm{C}$. All samples were weighted on the analytical balance before the analysis. The samples were transferred into sealed test tubes quickly, and $10 \mathrm{ml}$ of distilled water was added to each tube. The bone and tissue fragments remained on the bottom of the tube. All the analyses were performed with the solution (tissue liquid) in the upper part.

Preparation of Calibration Samples for Dexamethasone: For calibration solution, $1 \mathrm{~mL}$ of solution including $4 \mathrm{mg} / \mathrm{mL}$ of dexamethasone (Dexoject) was taken. Stock solution was obtained by diluting to $500 \mathrm{~mL}$ with distilled water. Respectively, $1 \mathrm{~mL}, 3 \mathrm{~mL}, 5 \mathrm{~mL}, 8 \mathrm{~mL}, 12 \mathrm{~mL}, 16 \mathrm{~mL}$, and $20 \mathrm{~mL}$ were taken from this solution, and each quantity was filled to $20 \mathrm{ml}$ with distilled water. The solution concentration $\mathrm{ppm}$ values were calculated as, respectively, $8 \mathrm{ppm}, 24 \mathrm{ppm}, 40 \mathrm{ppm}, 64 \mathrm{ppm}$, $96 \mathrm{ppm}, 128 \mathrm{ppm}$, and $160 \mathrm{ppm}$ (ppm: a mg of substance in 1 liter solution). Absorbance values of prepared samples were measured in Perkin Elmer Lambda 25 UV-VIS brand spectrophotometer quartz tubes at $214 \mathrm{~nm}, 236 \mathrm{~nm}$, and $240 \mathrm{~nm}$, which showed maximum absorbance. These three obtained absorbance values were used to calculate the ppm values of the unknown samples. From the prepared calibration curve using the method of linear regression, equations that bound absorbance to concentration were found separately for each wavelength. The formula obtained from the $240 \mathrm{~nm}$ wavelength was used because it gave the best results: $\mathrm{A}=(0.010 \mathrm{xC})+0.016$; where $\mathrm{A}=$ absorbance and $\mathrm{C}=$ concentration.

The concentration value that corresponds to the absorbance value at $240 \mathrm{~nm}$ was calculated in ppm for dexamethasone. The Statistical Package for the Social Sciences (SPSS) version 18 (SPSS Inc. Chicago, IL, USA) was used for statistical analysis. The Wilcoxon paired two-sample test was used to compare the groups.

\section{Results}

Each experiment group consisted of 5 Hartley strain albino guinea pigs. The calculated average concentrations of the right 
and left ears are plotted in Table 1. When we compared these averages, there was a statistically significant difference between the right and left ears in Exp 1, but there was no difference in Exp 2.

Various drug concentrations in different parts of the inner ear are shown in Table 2. The drug distribution in Exp 1 and 2 is shown in Figures 2 and 3, as well. Although dexamethasone concentrations were higher in the basal turn and vestibule in Exp 1, there was no statistical difference among different parts of the inner ear. The lowest concentration was observed in the apex. There was also no statistically significant difference in Exp 2 , but the highest concentrations were found in the vestibule and apex. There was also a high amount of dexamethasone in the basal turn. Interestingly, we found a high dexamethasone concentration in the vestibule of the control ear after 2 hours.

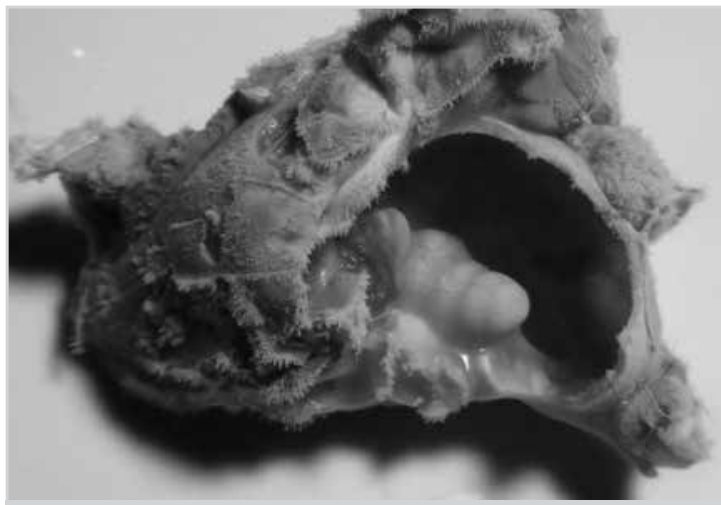

Figure 1. Frozen temporal bone of a guinea pig just before the dissection

\section{Discussion}

There are different kinds of sampling methods in the literature. Some authors obtained the samples directly from the round window. They aspirated a total of $10 \mu \mathrm{l}$ perilymph from the scala tympani $(4,5)$. Others had an additional sample from the scala vestibuli of the basal turn by drilling the bone $(8,9)$. Single sampling methods from the round window made us calculate only the concentration of the drug in the scala tympani $(4,5)$. The method did not lead us to estimate the distribution in the inner ear. The proposed solution for this problem was the use of markers and tissue-processing methods (3). After the IT application, the temporal bones were immunohistochemically stained for dexamethasone 21-phosphate, dexamethasone, and the glucocorticoid receptor. They found that the drug reached the cochlea in 15 minutes and the highest point at 1 hour. The spiral ligament, organ of Corti, spiral ganglion, and vestibular sensory epithelia were found to be positive (3). But this solution did not give detail regarding the concentration in different regions. Then the revolutionary apical sampling method was introduced (10-12). They thought that taking small samples one by one from a hole drilled to the apical region of the cochlea minimized the cerebrospinal fluid contamination. All these methods have some weak sides, like dealing with the liquids. Liquids are easily transferred from one point to another and fill all the empty spaces easily. Also, molecules dissolved in the liquids tend to distribute evenly in all parts of the liquid and react to the changes quickly. Thus, sampling from one point of the inner ear will make the cerebrospinal fluid move to the inner ear instantly. Then, dissolved molecules in perilymph have a new distribution, and the concentration of molecules changes. Plontke et al. $(7,13)$ used computer simulations to solve this

Table 1. The average of all calculated values (ppm) was plotted according to groups' different time points (Exp 1 [0.5 hours], Exp 2 [2 hours])

\begin{tabular}{l|l|l|c|c|c}
\hline & Group & $\mathbf{n}$ & Mean \pm std & Median (Min-Max) & Significance \\
\hline Exp 1 & dex & 5 & $25.1 \pm 13.39$ & $19.59(10.18-42.38)$ & $\mathrm{p}=0.043$ \\
\hline & control & 5 & $6.37 \pm 4.7$ & $5.69(0-12.36)$ & $\mathrm{p}=0.345$ \\
\hline Exp 2 & dex & 5 & $24.31 \pm 29.68$ & $12.98(0-26.49)$ & \\
\hline
\end{tabular}

Dex: dexamethasone

Table 2. Concentration values (ppm) of different inner ear parts. The left side of the table indicates the left ear (dexamethasone) and the right side the right ear (control) results

\begin{tabular}{|c|c|c|c|c|c|}
\hline Dex & Mean \pm Std & Median (Min-Max) & Median (Min-Max) & Mean \pm Std & Control \\
\hline $0.5 \mathrm{~h}$ basal & $8 \pm 6.69$ & $9.19(0.08-16.87)$ & $0.51(0-5.7)$ & $1.74 \pm 2.44$ & $0.5 \mathrm{~h}$ basal \\
\hline 0.5 h 2.turn & $3.57 \pm 3.74$ & $1.61(0.81-9.73)$ & $1.9(0-3.22)$ & $1.67 \pm 1.48$ & 0.5 h 2.turn \\
\hline $0.5 \mathrm{~h}$ apex & $2.52 \pm 4.04$ & $0.69(0-9.53)$ & $0(0-1.62)$ & $0.37 \pm 0.71$ & $0.5 \mathrm{~h}$ apex \\
\hline $0.5 \mathrm{~h}$ vestibule & $11.01 \pm 12.17$ & $6.25(2.85-32.37)$ & $0(0-11.56)$ & $2.58 \pm 5.05$ & $0.5 \mathrm{~h}$ vestibule \\
\hline $2 \mathrm{~h}$ basal & $11.57 \pm 20.72$ & $3.21(0.27-48.5)$ & $0.1(0-8.45)$ & $1.74 \pm 3.75$ & $2 \mathrm{~h}$ basal \\
\hline 2 h 2.turn & $2.17 \pm 3.41$ & $0.51(0-8.09)$ & $0(0-17.3)$ & $4.3 \pm 7.49$ & 2 h 2.turn \\
\hline $2 \mathrm{~h}$ apex & $5.91 \pm 4.39$ & $4.7(1.24-11.09)$ & $0.63(0-3.53)$ & $1.41 \pm 1.67$ & $2 \mathrm{~h}$ apex \\
\hline $2 \mathrm{~h}$ vestibule & $4.65 \pm 3.89$ & $4.32(0.1-9.32)$ & $3.9(0-19.3)$ & $5.6 \pm 7.97$ & $2 \mathrm{~h}$ vestibule \\
\hline
\end{tabular}




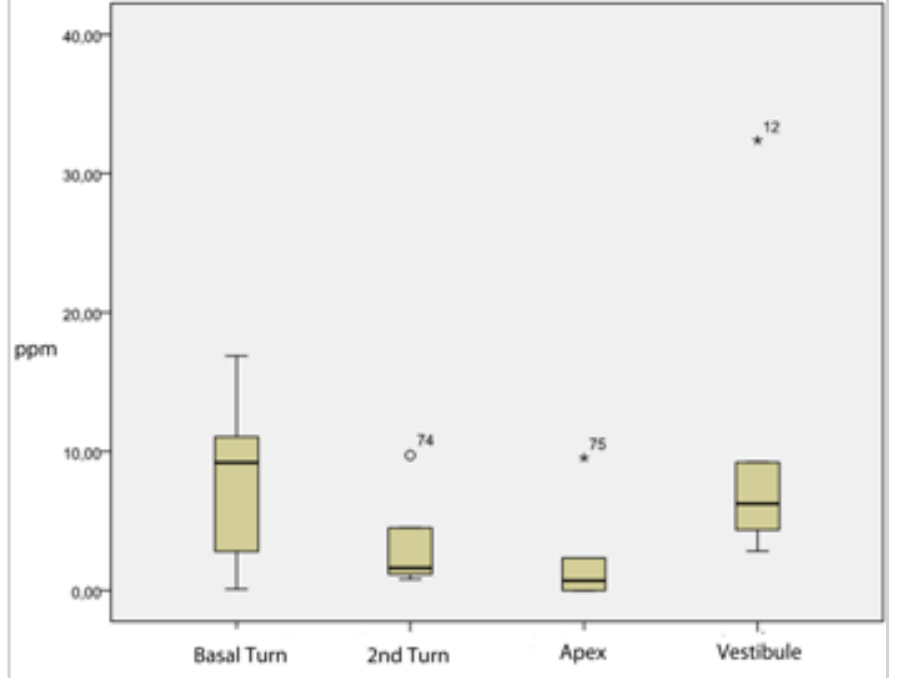

Figure 2. Drug concentrations in the left ear in Exp 1 (0.5 hour)

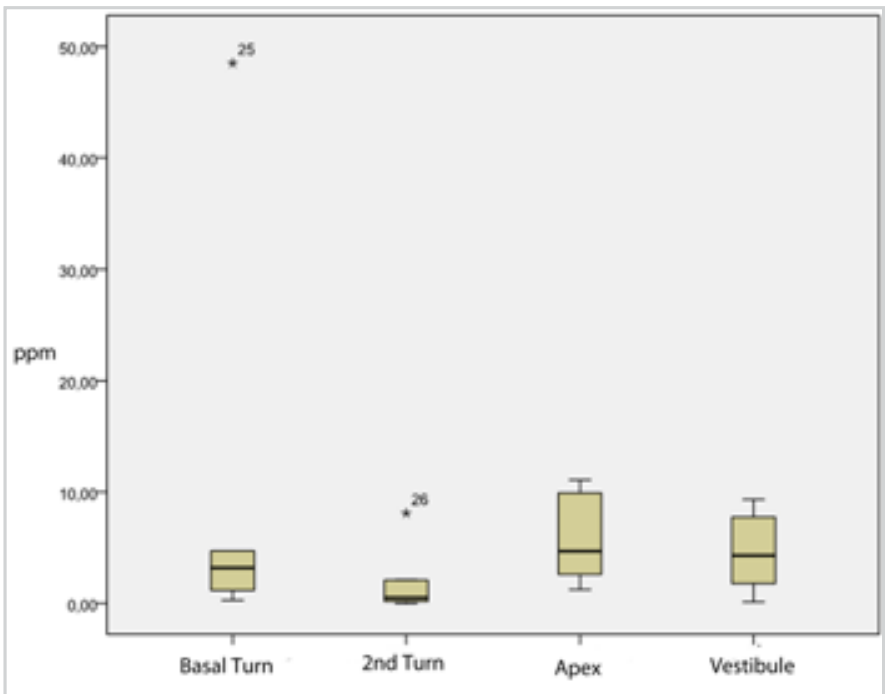

Figure 3. Drug concentrations in the left ear in $\operatorname{Exp} 2$ (2 hours)

problem and to calculate drug amount throughout to cochlea. They reported that the mean basal-apical concentration gradient was calculated approximately as 17,000 by the finite element computer model (10). We tried to use the freezing method to overcome this situation. In our method, we cut the sections after freezing the inner ear. Thus, there was no liquid contamination.

In all the methods, samples were taken from only one scala. Our model shows the total drug amount of the three scalas (tympani, media, and vestibuli). This is sometimes an advantage, and sometimes it is not. It changes according to required answers.

Finding high concentrations in the basal region was consistent with other studies showing that cellular effects were more prominent in the basal turn than in the apex of cochlea $(14,15)$. We also found dexamethasone in all parts of the inner ear. The basal turn and vestibule were found to have higher concentrations in a short time. But after two hours, the apex was the prominent instead of the basal turn, while vestibule preserved its concentration. But our calculations did not match the concentration gradients calculated by Plontke et al. $(7,13)$ The question about the difference between the basal and apical region still remains.

Another issue considering the IT drug application was to determine how long the drug stays in the target region. Changes in the concentration were found at two hours in this study. But it is not clear what happens beyond that time. One of the limitations of our study was that the concentration calculations were not studied beyond two hours. It was demonstrated that IT dexamethasone passed to the inner ear in 15 minutes, reaching the highest levels at the first hour, and it disappeared completely in 24 hours (3).

Another limitation to our study might be the diffusion of the drug through the bone of the otic capsule in guinea pigs. Mikulec et al. (16) applied gentamicin and the marker trimethylphenylammonium using two different methods. First, they filled the bulla; second, they put the drugs limited to the round window only. They found that drug concentration increased more in the bulla group than in the round-window-only group (16). They concluded that some of the drug might have passed through the bony labyrinth. But in our study, in $\operatorname{Exp} 1$, we found low values in the apical and the second turn region, and had the bone diffusion been prominent, we would have found higher values.

The interesting part is that the control ear also showed slightly elevated drug levels in the vestibule after two hours. The most probable explanation for this situation is the contamination via Eustachian tube.

In our study, we used the UV spectroscopy method. This technique is often used in chemical measurement, and the margin of error is very low. We could not obtain desired results in some guinea pigs clearly. The standardization of the samples and the amount of the drug absorbed by the tissues might be the source of error.

\section{Conclusion}

In this preliminary study, a new animal model was established for analyzing the distribution and amount of the drug in the inner ear. We found that dexamethasone would reach the apical part of the cochlea in two hours, even in the case of 0.5 hour contact time on the round window. But the concentration was never as high as in the basal part of the cochlea. During two hours, the vestibule contained the drug constantly. Regardless of the limitations, different drugs can be used in this model before clinical applications.

Ethics Committee Approval: Ethics committee approval was received for this study from the Ethics Committee of Pamukkale University School of Medicine (Date: 08.01.2013, No: 2013/01)

Informed Consent: Not applicable.

Peer-review: Externally peer-reviewed.

Author Contributions: Concept - K.A., F.N.A.; E.E., C.O.K., F.T., E.Y., M.A.; Design - K.A., F.N.A.; E.E., C.O.K., F.T., E.Y., M.A.; Supervision - K.A., F.N.A.; E.E., C.O.K., F.T., E.Y., M.A.; Resource - 
Aykal et al.

K.A., F.N.A.; E.E., C.O.K., F.T., E.Y., M.A.; Materials - K.A., F.N.A.; E.E., F.T., E.Y., M.A.; Data Collection and/or Processing - K.A., F.N.A.; E.E., C.O.K., F.T., E.Y., M.A.; Analysis and/or Interpretation - K.A., F.N.A.; E.E., M.A.; Literature Search - K.A., F.N.A.; E.E., C.O.K., F.T., E.Y., M.A.; Writing - K.A., F.N.A.; E.E., M.A.; Critical Reviews - K.A., F.N.A.; E.E., C.O.K., F.T., E.Y., M.A.

Conflict of Interest: The authors have no conflicts of interest to declare.

Financial Disclosure: The study was supported by Pamukkale University Scientific Research Fund (Project no: PAÜBAP-1446).

\section{References}

1. Swan EE, Mescher MJ, Sewell WF, Tao SL, Borenstein JT. Inner ear drug delivery for auditory applications. Adv Drug Deliv Rev 2008; 60: 1583-99. [CrossRef]

2. Rarey KE, Curtis LM. Receptors for glucocorticoids in the human inner ear. Otolaryngol Head Neck Surg 1996; 115: 38-41. [CrossRef]

3. Hargunani CA, Kempton JB, DeGagne JM, Trune DR. Intratympanic injection of dexamethasone: time course of inner ear distribution and conversion to its active form. Otol Neurotol 2006; 27: 564-9. [CrossRef]

4. Chandrasekhar SS, Rubinstein RY, Kwartler JA, Gatz M, Connelly PE, Huang E, et al. Dexamethasone pharmacokinetics in the inner ear: comparison of route of administration and use of facilitating agents. Otolaryngol Head Neck Surg 2000; 122: 521-8. [CrossRef]

5. Yang J, Wu H, Zhang P, Hou DM, Chen J, Zhang SG. The pharmacokinetic profiles of dexamethasone and methylprednisolone concentration in perilymph and plasma following systemic and local administration. Acta Otolaryngol 2008; 128: 496-504. [CrossRef]

6. Mynatt R, Hale SA, Gill RM, Plontke SK, Salt AN. Demonstration of a longitudinal concentration gradient along scala tympani by sequential sampling of perilymph from the cochlear apex. J Assoc Res Otolaryngol 2006; 7: 182-93. [CrossRef]

7. Plontke SK, Wood AW, Salt AN. Analysis of gentamicin kinetics in fluids of the inner ear with round window administration. Otol Neurotol 2002; 23: 967-74. [CrossRef]

8. Parnes LS, Sun AH, Freeman DJ. Corticosteroid pharmacokinetics in the inner ear fluids: an animal study followed by clinical application. Laryngoscope 1999; 109: 1-17. [CrossRef]

9. Liu HJ, Dong MM, Chi FL. Dexamethasone pharmacokinetics in Guinea pig inner ear perilymph. ORL J Otorhinolaryngol Relat Spec 2006; 68: 93-8. [CrossRef]

10. Plontke SK, Biegner T, Kammerer B, Delabar U, Salt AN. Dexamethasone concentration gradients along scala tympani after application to the round window membrane. Otol Neurotol 2008; 29: 401-6. [CrossRef]

11. Plontke SK, Mynatt R, Gill RM, Borgmann S, Salt AN. Concentration gradient along the scala tympani after local application of gentamicin to the round window membrane. Laryngoscope 2007; 117: 1191-8. [CrossRef]

12. Hahn H, Salt AN, Biegner T, Kammerer B, Delabar U, Hartsock JJ, et al. Dexamethasone levels and base-to-apex concentration gradients in the scala tympani perilymph after intracochlear delivery in the guinea pig. Otol Neurotol 2012; 33: 660-5. [CrossRef]

13. Plontke SK, Salt AN. Quantitative interpretation of corticosteroid pharmacokinetics in inner fluids using computer simulations. Hear Res 2003; 182: 34-42. [CrossRef]

14. Pender DJ. Gentamicin tympanoclysis: effects on the labyrinthine sensory cells. Laryngoscope 2003; 113: 343-8. [CrossRef]

15. Sha SH, Taylor R, Forge A, Schacht J. Differential vulnerability of basal and apical hair cells is based on intrinsic susceptibility to free radicals. Hear Res 2001; 155: 1-8. [CrossRef]

16. Mikulec AA, Plontke SK, Hartsock JJ, Salt AN. Entry of substances into perilymph through the bone of the otic capsule after intratympanic applications in guinea pigs: implications for local drug delivery in humans. Otol Neurotol 2009; 30: 131-8. [CrossRef] 